\title{
CONVERGENT GAINS OF RED CAROTENOID-BASED COLORATION IN THE NEW WORLD BLACKBIRDS
}

\author{
Nicholas R. Friedman, ${ }^{1,3}$ Lynna M. Kiere, $^{2}$ and Kevin E. Omland ${ }^{1}$ \\ ${ }^{1}$ Department of Biological Sciences, University of Maryland-Baltimore County, 1000 Hilltop Circle, Baltimore, Maryland 21250, USA; and \\ ${ }^{2}$ Laboratorio de Conducta Animal, Instituto de Ecología, Universidad Nacional Autónoma de México, Ciudad Universitaria, Mexico
}

\begin{abstract}
Many birds have colorful plumage ornaments that utilize carotenoid pigments, and these are often displayed in signaling contexts. Researchers in behavioral ecology have focused on examining carotenoids in general, and red carotenoids in particular, because they may be an honest index of individual condition or quality. However, few studies have examined the evolutionary changes in carotenoid-based coloration across a phylogeny. We used reflectance spectrometry to examine carotenoid-based coloration across the New World blackbirds (Icteridae). We scored discrete character states based on these measurements and mapped them onto the icterid phylogeny. Our results indicate that red coloration has been gained six times in the blackbirds from a common ancestor that exhibited yellow ornamentation. This result was supported by both parsimony and likelihood methods of ancestral state reconstruction and by each of three different scoring methods. Thus, multiple lineages of icterids have convergently evolved red patches from a common ancestor that most likely used yellow. Several other studies have observed repeated gains of red coloration, which suggests that our observations may reflect a directional trend common among avian clades. Received 26 May 2011, accepted 19 August 2011.
\end{abstract}

Key words: ancestral state reconstruction, carotenoids, convergent evolution, Icteridae, plumage coloration.

\section{Adquisiciones Convergentes de Coloraciones Basadas en Carotenoides Rojos en los Ictéridos}

RESUMEN.-Muchas aves tienen ornamentos coloridos de plumaje formados con pigmentos carotenoides, que frecuentemente son utilizados en un contexto de señalización. Estos pigmentos, en particular los carotenoides rojos, han recibido especial atención por parte de los ecólogos de la conducta porque pueden ser un indicador honesto de la condición o calidad individual. Sin embargo, pocos estudios han utilizado una filogenia para investigar los cambios evolutivos en la coloración basada en carotenoides. En este estudio, utilizamos espectrometría de reflectancia para examinar la coloración basada en carotenoides en las aves de la familia Icteridae. Con base en estas mediciones, calificamos distintos estados discretos del caracter y los mapeamos sobre la filogenia de la familia. Nuestros resultados indican que en la familia Icteridae la coloración roja ha surgido seis veces a partir de un ancestro común que tenía ornamentación amarilla. Este resultado es apoyado por dos métodos de reconstrucción de estados ancestrales - parsimonia y máxima verosimilitud- y además es consistente entre tres distintos métodos de calificación. Por lo tanto, varios linajes de Icteridae han evolucionado los parches rojos de manera convergente a partir de un ancestro común que probablemente utilizaba pigmentos amarillos. Varios otros estudios han observado ganancias repetidas del color rojo, lo que sugiere que nuestras observaciones pueden reflejar una tendencia direccional que es común entre los clados de aves.

DIFFERENT SPECIES OF birds often vary greatly in plumage coloration even when closely related. Understanding the historical origins of this variation can inform the study of both the mechanisms that produce plumage coloration and the functions that such coloration may perform. Carotenoid pigments are responsible for many of the red, orange, and yellow hues that are visible in feathers across a wide range of avian taxa (McGraw 2006a). Feather patches ornamented with carotenoids are used by many taxa in a signaling context (e.g., Murphy et al. 2009, Yasukawa et al. 2009). Studies of intraspecific variation in carotenoid-based coloration have shown that in many cases this coloration is dependent on the signaler's condition (Dale 2006, and references therein). Indeed, saturation of carotenoid-based coloration may often be a sexually selected trait, as studies of House Finches (Carpodacus mexicanus) and widowbirds (Euplectes spp.) have demonstrated (Hill 1990, Pryke et al. 2001). However, there have been few studies of how carotenoid-based colors vary among species or how this variation has evolved.

The mechanisms underlying carotenoid-based coloration are complex (McGraw 2006a). Birds synthesize melanins endogenously (McGraw 2006b) but must obtain carotenoids from dietary sources (Fox 1962). Birds may deposit the carotenoid compounds they acquire from the diet (e.g., lutein, zeaxanthin) into their feathers directly (Brush 1990). For example, Yellow

${ }^{3}$ E-mail: friedmn1@umbc.edu

The Auk, Vol. 128, Number 4, pages 678-687. ISSN 0004-8038, electronic ISSN 1938-4254. @ 2011 by The American Ornithologists' Union. All rights reserved. Please direct all requests for permission to photocopy or reproduce article content through the University of California Press's Rights and Permissions website, http://www.ucpressjournals. com/reprintInfo.asp. DOI: 10.1525/auk.2011.11117 
Warblers (Setophaga petechia) use only lutein and zeaxanthin to color their yellow feathers (McGraw 2006a). Alternatively, some birds may chemically alter dietary carotenoids to form new modified carotenoid compounds that often have different absorbance spectra than the originals (e.g., astaxanthin, canthaxanthin; Fox et al. 1969, Inouye et al. 2001). For example, male Scarlet Tanagers (Piranga olivacea) use the common dietary pigment zeaxanthin to produce their yellow basic plumage but convert these pigments to canthaxanthin for use in their red alternate plumage (Brush 1967).

Many red-ornamented birds produce their plumage coloration by modifying their predominantly yellow dietary carotenoids to form red ones (Brush and Power 1976; Hill 1996, and references therein). Among these, House Finches provide a wellstudied example of this phenomenon. Despite the presence of only four carotenoid pigments in their diet and plasma, House Finches deposit 11 unique carotenoid compounds into their feathers, six of which are red keto-carotenoids. Several researchers have suggested that the gain of such pigment-modification mechanisms may be responsible for evolutionary transitions from yellow to red plumage (Hudon 1991, Kiere et al. 2009). Indeed, chemical analysis of feather pigmentation in bishops (Euplectes spp.) has demonstrated that red coloration has evolved in that clade through a gain of red keto-carotenoids (Andersson et al. 2007, Prager and Andersson 2010).

Many recent studies have focused on describing the proximate and ultimate mechanisms underlying intraspecific variation in carotenoid coloration (see Dale 2006, McGraw 2006a). However, studies are needed that address variation in carotenoid coloration from a phylogenetic perspective. By examining the historical changes in coloration that have led to the variation seen in extant species, phylogenetic studies can reveal interesting patterns of trait evolution and provide predictions about the evolutionary processes that underlie them (e.g., developmental constraint in the evolution of oriole plumage pattern; Omland and Lanyon 2000). For example, a series of studies examining song and plumage evolution in two blackbird clades, the New World orioles and the caciques and oropendolas (Cacicus, Psarocolius, Gymnostinops, and Ocyalus), found that degrees of homoplasy appeared to vary with mating system (Omland and Lanyon 2000, Price et al. 2007, Price and Whalen 2009). Studies of color and tail evolution in the bishops and widowbirds have found evidence of an apparent trend toward gains of red coloration (Prager et al. 2009, Prager and Andersson 2010). Patterns such as these demand further investigation and provide a unique opportunity to study the implications of sexual selection at a macroevolutionary scale.

The New World blackbirds (Icteridae) display a full range of carotenoid-based plumage colors and ornaments, making them an ideal system in which to study the evolution of these characteristics. Many previous studies have used the Icteridae as a model clade to study the evolution of mating systems, migratory behavior, plumage coloration, and vocal behavior (Searcy et al. 1999, Omland and Lanyon 2000, Price and Lanyon 2002, Hofmann et al. 2006, Kondo and Omland 2007, Price et al. 2007, Price and Whalen 2009). Furthermore, many previous studies have examined the phylogenetic relationships of the New World blackbirds, which are supported by both mitochondrial and nuclear markers (Lanyon and Omland 1999, Allen and Omland 2003, Price et al. 2009, Jacobsen et al. 2010). Model clades such as the Icteridae provide a unique opportunity for comparative studies to utilize existing data (e.g., Friedman et al. 2009). Here, we build upon previous work on carotenoid-based coloration in the New World orioles (Hofmann et al. 2006) and the Cacicus group (Kiere et al. 2009) and expand this taxonomic coverage to include the entire blackbird family.

Taxa with red carotenoid-colored plumage are uncommon among icterids, appearing in fewer than 20 of 101 recognized species (Jaramillo and Burke 1999, Clements 2007). However, such red-displaying taxa are found in three of four clades in the Icteridae (Lanyon and Omland 1999). This pattern is most likely due to homoplasy, the presence of similar traits not derived from a common ancestor. However, it is unclear whether it was convergent gains or losses that dominated the history of red plumage in blackbirds. Because red coloration is far less common than yellow among extant taxa, it may be likely that repeated gains of red should explain this pattern. However, this and other such predictions are not inferences, and the methods and assumptions involved in inferring ancestral characteristics are not trivial. Consequently, in the present study we aimed to rigorously test these alternatives: that the Icterids had (1) a yellow common ancestor and repeated gains of red or (2) a red common ancestor with repeated losses of red explaining the distribution of colors across extant taxa.

We used reflectance spectrometry and ancestral state reconstruction to examine patterns in the evolution of red coloration across the New World blackbirds. Our goals were to (1) infer ancestral states for carotenoid coloration across the Icteridae, (2) distinguish whether carotenoid-based red coloration was repeatedly gained or lost in Icteridae, and (3) determine the color of the ancestral blackbird.

\section{Methods}

Color measurement.-We measured carotenoid-based coloration across Icteridae using reflectance spectrometry. Reflectance spectrometry is a widely used method for quantifying color because it describes color without respect to the spectral sensitivities of any particular visual system (Andersson and Prager 2006). Many previous studies performed by our research group have used reflectance spectrometry to measure feather coloration (Hofmann et al. 2006, 2007a, b; Kiere et al. 2009). We built on these previous studies by using reflectance spectra from studies that measured color variation in the orioles (Hofmann et al. 2006) and the caciques (Kiere et al. 2009). Consequently, to produce new reflectance spectra for the remaining icterids, we followed the techniques used in these previous studies.

Specifically, we used an Ocean Optics USB2000 reflectance spectrometer in conjunction with a PX-2 pulsed xenon light source to perform these measurements (Ocean Optics, Dunedin, Florida), calibrated against a white Spectralon standard (Labsphere, North Sutton, New Hampshire). We measured approximately five male museum skins for each taxon (mean $4.6 \pm 1.21$ [SD]; Table 1). For taxa in which a breeding season has been described (Jaramillo and Burke 1999), we preferentially sampled specimens collected during this time of the year. Furthermore, to avoid measuring birds displaying immature plumage, we attempted to use individuals collected after their second year, as identified by molt or plumage (Pyle 1997, Jaramillo and Burke 1999). Finally, we attempted to sample individuals from multiple locations across each 


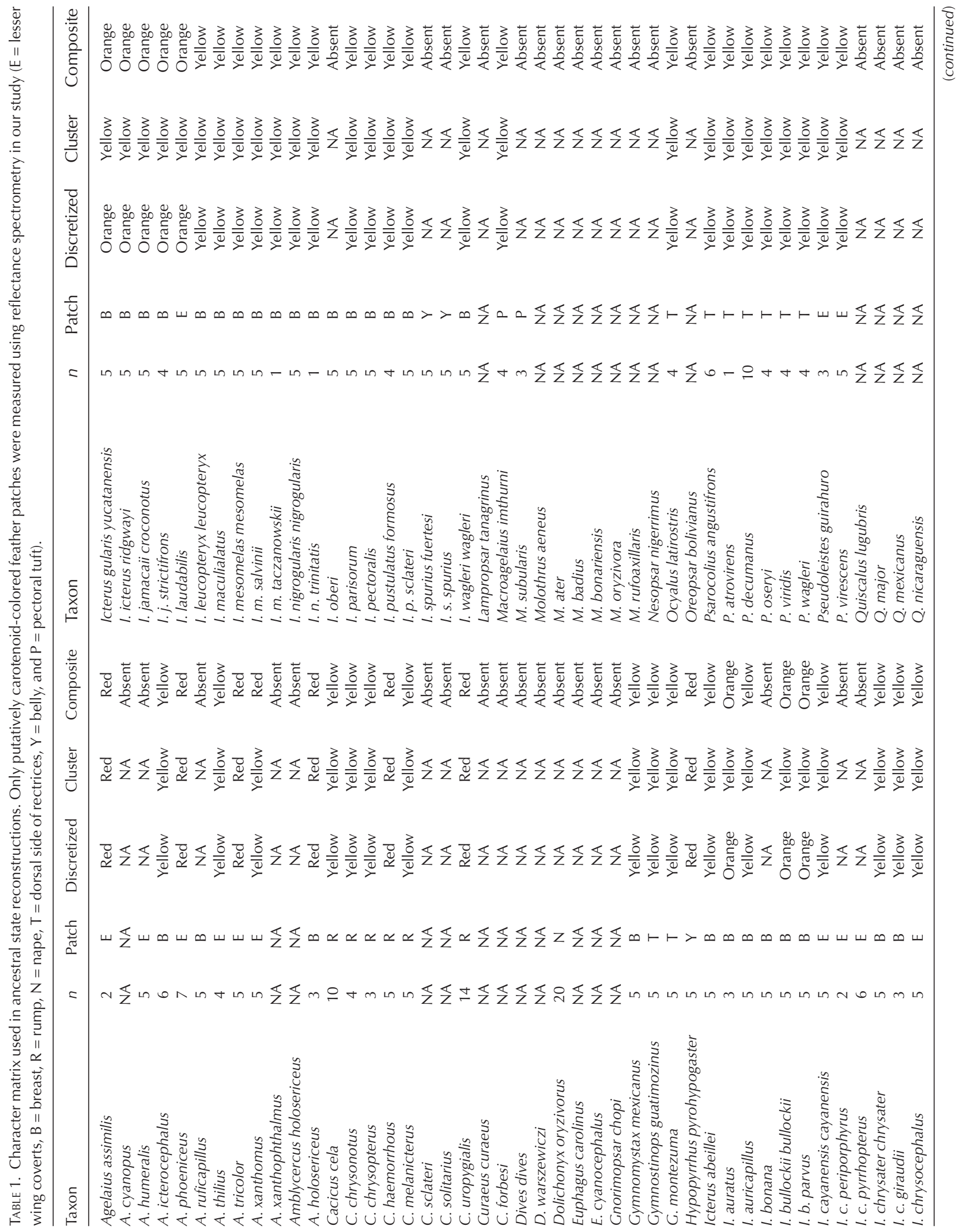




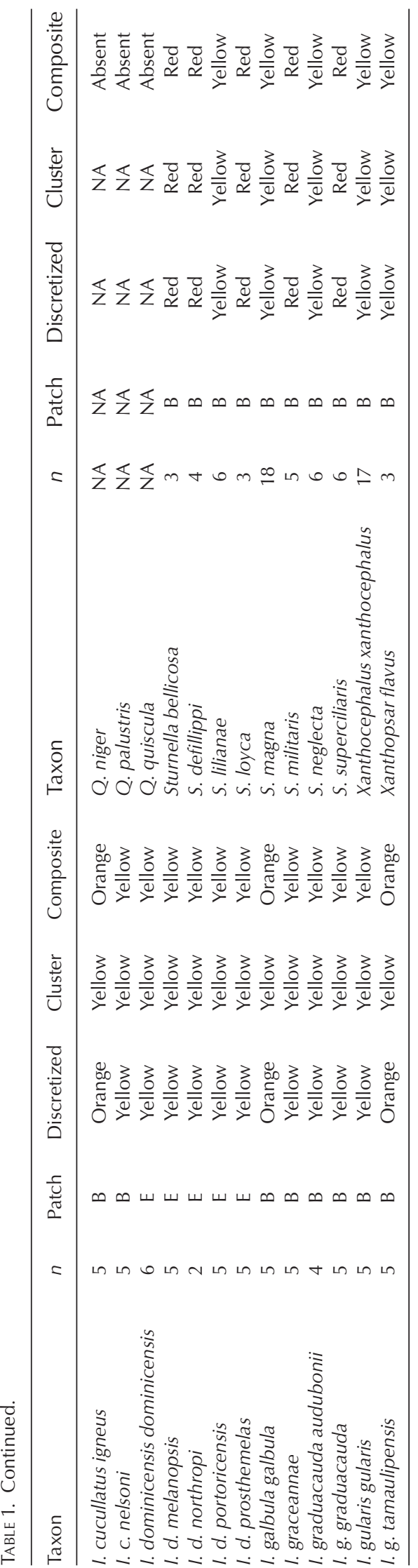

taxon's range. We performed three replicate measurements of each body region (see Andersson and Prager 2006) that appeared red, orange, or yellow. We also measured feathers that were blond, rusty, or chestnut to determine the presence or absence of carotenoid spectra (see below). We recorded and processed the resulting spectra using OOIBASE software and a supplemental program provided by T. H. Chiou and T. W. Cronin.

Character scoring.-Scoring methods in color measurement are vital to studies of feather coloration, and many approaches have been described (Montgomerie 2006). We scored two characters describing feather color: (1) pigment use as either "carotenoid" or "melanin" and (2) carotenoid coloration as "red," "orange," or "yellow." The differences between colors produced by carotenoid and melanin pigments are qualitative and can be diagnosed on the basis of reflectance spectra (Fig. 1; see Hofmann et al. 2007a, b). We scored taxa that were described as entirely black as using melanic pigmentation (Jaramillo and Burke 1999). To score the presence of carotenoids or melanins, we followed the methods of Hofmann et al. (2006). They defined the characteristics of carotenoid plumage as having a maximum reflectance $>10 \%$, with a sigmoid spectral shape and an ultraviolet (UV) peak (further described in Hofmann et al. 2007a, b). By contrast, melanins produce no UV peak but instead produce a spectrum wherein reflectance steadily increases with wavelength but does not plateau (Fig. 1). One drawback of measuring carotenoid coloration with reflectance spectrometry is that any carotenoids masked by melanin pigments may not be detectable (Hofmann 2007b). We acknowledge that small quantities of phaeomelanin may be present in some plumage scored here as carotenoid-based and vice versa (McGraw et al. 2004). However, our intent here was not to comprehensively score melanin-based plumage but rather to effectively score carotenoid-based coloration as absent when melanin-based coloration was observed instead.

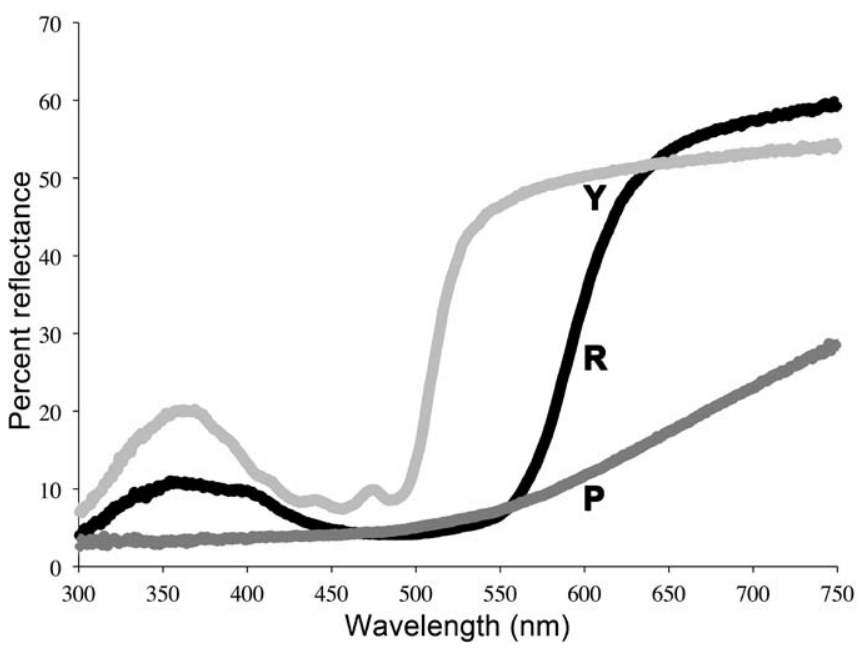

FIG. 1. Reflectance spectra from example specimens of a yellow (Y) carotenoid-based feather patch from a male Eastern Meadowlark (Sturnella neg/ecta), a red $(R)$ carotenoid-based feather patch from a male Military Blackbird (S. militaris), and a chestnut (P) phaeomelanin-based feather patch from a male Orchard Oriole (Icterus spurius). 
AUK, VOL. 128

We measured reflectance spectra for all apparently carotenoid-pigmented feather patches on a total of 362 museum skins sampled across 86 icterid species and subspecies (70 out of 101 species described in Clements 2007; specimen voucher numbers are reported in Table S1, an online supplement; see Acknowledgments). Carotenoid coloration is found on different body regions across icterid species. For example, meadowlarks have yellow or red breasts, whereas caciques have yellow or red rumps (Jaramillo and Burke 1999). Consequently, we compared the color of whichever feather patch was most consistently carotenoid-colored for that clade (see Table 1). We examined hue by taking the reflectance midpoint ( $\lambda_{\mathrm{R} 50}$; hereafter "spectral location") of each reflectance spectrum (Pryke et al. 2001, Andersson and Prager 2006, Hofmann et al. 2006, Montgomerie 2006). In addition, we calculated a measure of "yellow chroma" (representing color "purity"; see Montgomerie 2006). This measure was specific to an arbitrarily defined portion of the typical carotenoid reflectance curve that described percent reflectance in the green to yellow portion of the spectrum (500-600 nm). "Red" chroma has been measured this way in previous studies (Norris et al. 2004, Shawkey and Hill 2005) and our yellow chroma measurement is a simple extension of its concept.

We used three methods to delineate discrete character states from continuous measures of color. First, we used areas of nonoverlap among intervals of standard error for character values following the methods of Price and Lanyon (2002). This simple technique has been used to delineate discrete character states from continuous measures of both song (Price et al. 2007) and plumage (Kiere et al. 2009). Because all non-oriole blackbirds could be scored only as either red or yellow in color (see Fig. 2; also see Kiere et al. 2009), we used non-oriole taxa to describe three character states. We defined "red" and "yellow" states by the range of variation included within standard error intervals of non-oriole blackbirds and we defined "orange" as the intermediate range, which is only occupied by several orioles (this method is hereafter referred to as "discretized" scoring). Second, we scored a composite character that combines the discrete scoring with a fourth state to indicate when a taxon was found to use only melanin-based coloration (hereafter "composite" scoring). Third, we used a bivariate cluster analysis in $\mathrm{R}$ (CLUSTER) to assign taxa to different color groups (hereafter "cluster" scoring; Maechler 2005; Fig. 3). We estimated a dissimilarity matrix among taxa with respect to their spectral location and yellow chroma. We then used the "Partitioning around Medioids" operation in CLUSTER to describe the fit into one, two, three, four, and five clusters. This procedure is analogous to the $k$-means method of cluster analysis (Maechler 2005), which has been used in previous studies of color (Friedman et al. 2009, Prager and Andersson 2010).

Ancestral state reconstruction.-We reconstructed discrete ancestral states for the three methods described above across the icterid molecular phylogeny (Lanyon and Omland 1999, Price et al. 2009). This tree was inferred from nucleotide sequences from two mitochondrial loci and four nuclear loci and has been used in previous comparative studies of the blackbird family (Price et al. 2009). For each reconstruction, we used both simple parsimony and maximum likelihood in MESQUITE (Maddison and Maddison 2010). We pruned all taxa lacking
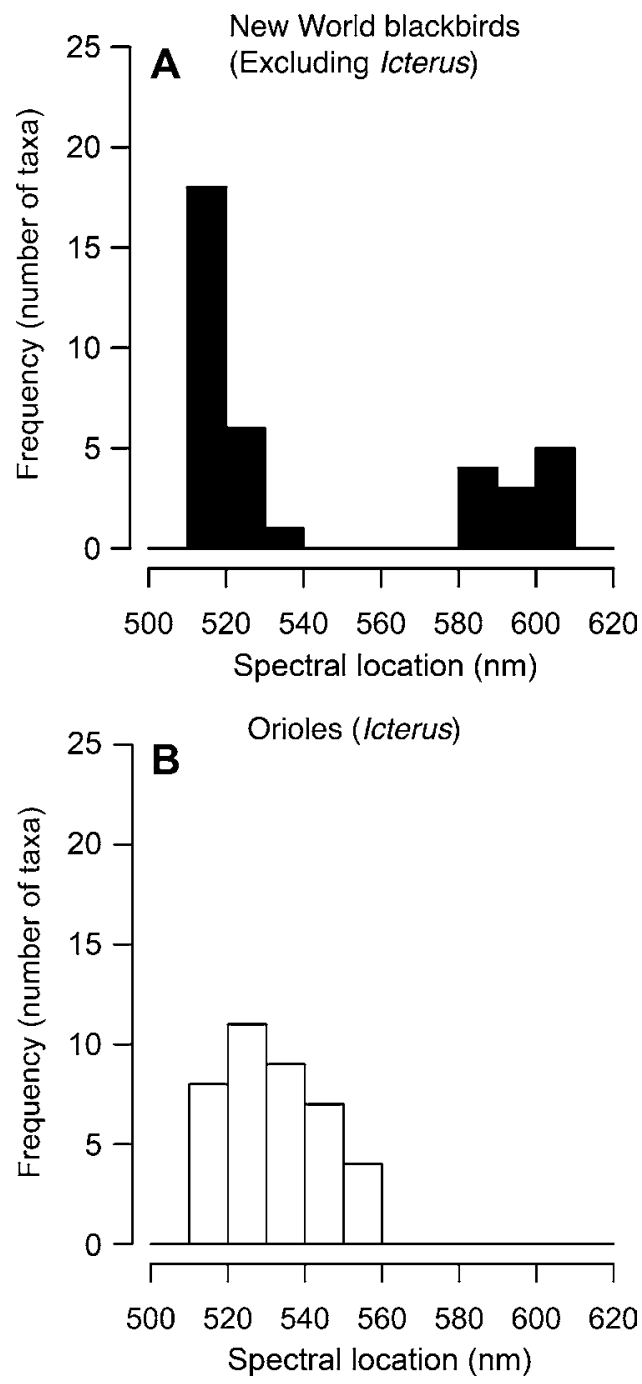

FIG. 2. Distribution of mean spectral location values for taxa across the New World blackbirds (A) excluding the orioles and (B) across the orioles. Note the absence of any icterid taxa with spectral locations from 560 to $570 \mathrm{~nm}$. This indicates that there are no icterids that display color patches with intermediate values between orange and red.

carotenoid-based ornamentation (38) from trees used to reconstruct the discretized and cluster characters but included these taxa for the reconstruction of the composite character. As recommended by Wiens et al. (2007), we explored the use of both one-parameter (gains and losses equal) and two-parameter (gains or losses more likely) models of character change with estimated rates. However, because of computational constraints, two-parameter rate models could be applied only to the binary character (i.e., the cluster character).

\section{Results}

Color variation.-We observed a bimodal distribution of taxonmean spectral location values across three of the icterid clades 


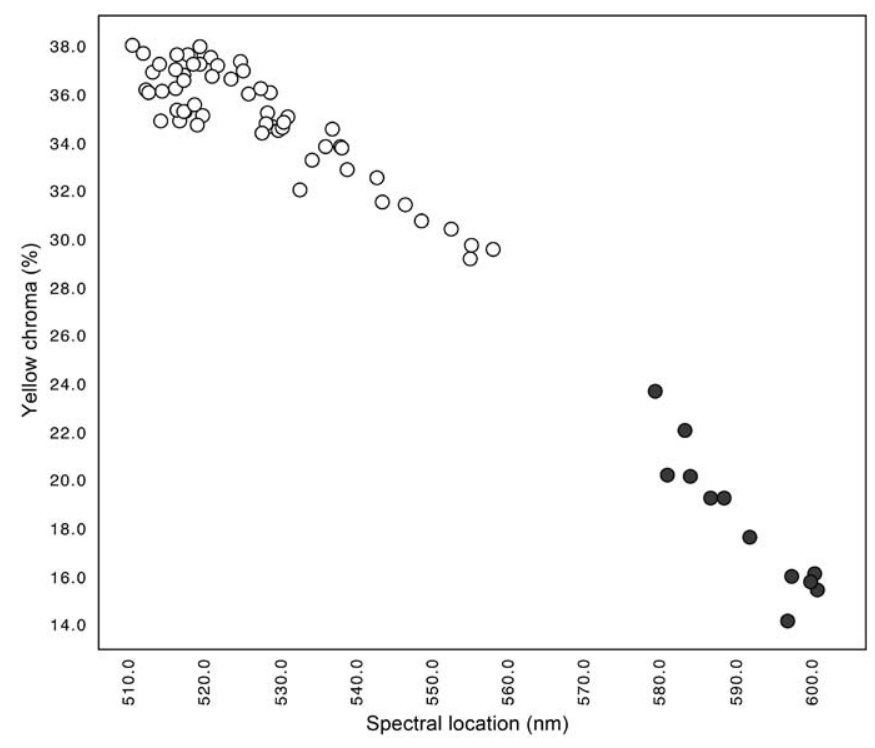

FIG. 3. Cluster analysis of two measures of carotenoid coloration: spectral location and yellow chroma. These two measurements are significantly correlated for carotenoid-colored patches (without phylogenetic correction; $\left.P<0.0001, R^{2}=0.94\right)$. Two groups were strongly supported; these are filled to indicate the "red" character state or open to indicate the "yellow" character state.

(Fig. 2A; $n=37$ ). However, this distribution was unimodal in the fourth clade, the New World orioles (Fig. 2B; $n=39$ ). Furthermore, only orioles exhibited plumage with spectral locations between $540 \mathrm{~nm}$ and $560 \mathrm{~nm}$, a range that roughly describes hues that humans perceive as orange. Yellow chroma values were highly correlated with spectral location values $\left(r^{2}=0.95\right)$ that ranged from $14 \%$ to $38 \%$ and produced a bimodal distribution similar to that of spectral location.

By examining standard error intervals we observed that outside of Icterus the "yellow" icterids varied in their spectral location from $509 \mathrm{~nm}$ to $537 \mathrm{~nm}$. We used this result to define our "yellow" character state by the range of 500-540 nm. We also observed that the "red" icterids varied in spectral location from $580 \mathrm{~nm}$ to $601 \mathrm{~nm}$. We used this result to define our "red" character state by the range of 580-605 $\mathrm{nm}$. We described birds exhibiting plumage with spectral location values in the intermediate range (540-580 nm) as having "orange" plumage. Following the standard error interval methods described above, we scored 52 icterid taxa as "yellow," 11 as "orange," and 12 as "red" (38 others were scored as melanin; see Table 1).

Cluster analysis of spectral location and yellow chroma revealed the presence of two highly significant groups ("red": $s_{i}=0.86$; "yellow": $s_{i}=0.77$; Fig. 3 ) that explained $100 \%$ of the observed color variation. All taxa were assigned to a group with a strong degree of confidence, with the exception of several taxa described by the discretizing method (Hofmann et al. 2006) as orange in color (e.g., I. cucullatus igneus). Furthermore, cluster analyses with three or more clusters yielded nonsignificant assignments (data not shown). All the taxa scored as red using this method (Hofmann et al. 2006) were also scored as "red" using the abovedescribed discretizing method (see Table 1).

Lastly, we scored 38 taxa as having no carotenoid-based coloration. Of these, the 10 taxa that displayed chestnut or blond colors all showed reflectance spectra with features suggesting that phaeomelanin was responsible for their hue. Thus, carotenoid coloration was scored as "absent" in these taxa.

Ancestral states.-Ancestral state reconstruction of the composite character using simple parsimony showed six independent gains of red coloration from a yellow common ancestor, with both yellow and red coloration repeatedly derived in the grackles and allies (Table 2 and Fig. 4). Analysis of the discretized character using parsimony showed a similar pattern but with five and six independent gains of red coloration being equally parsimonious (Table 2 and Fig. S1; Figs. S1-S4 are available as an online supplement; see Acknowledgments). In our parsimony reconstructions, we inferred seven gains of orange coloration in orioles but none in any other icterid clade. These all appeared to be recent gains, and orange coloration was only once a shared ancestral characteristic among any two oriole species. Ancestral state reconstruction of color using the cluster character also indicated a yellow ancestral icterid and five or six repeated gains of red carotenoid-based plumage in Icteridae (Table 2 and Fig. S2).

Likelihood estimates of ancestral states under a one-parameter model indicated six gains of red coloration from a common ancestor with yellow ornamentation for all scoring methods (Table 2 and Figs. 4 and S3). To support a scenario in which red coloration was ancestral, it was necessary to assume a model in which losses of red were at least $50 \times$ more likely than gains. Such a model was not supported by likelihood estimates of rate parameters $(P<0.0001)$.

TABLE 2. Results of ancestral state reconstructions in terms of gains and losses within the Icteridae, listed across scoring methods. For parsimony methods, we recorded both maximum and minimum numbers of gains and losses when equally parsimonious reconstructions were returned. For likelihood methods we used a likelihood decision threshold of 2.0. See text for likelihood model details.

\begin{tabular}{|c|c|c|c|c|c|c|c|c|c|}
\hline \multirow[b]{2}{*}{ Reconstruction method } & \multirow[b]{2}{*}{ Scoring } & \multicolumn{2}{|c|}{ Yellow } & \multicolumn{2}{|c|}{ Red } & \multicolumn{2}{|c|}{ Orange } & \multicolumn{2}{|c|}{ Melanin } \\
\hline & & Gains & Losses & Gains & Losses & Gains & Losses & Gains & Losses \\
\hline \multirow[t]{3}{*}{ Unordered parsimony } & Discretized & 0 & $13-14$ & $5-6$ & $0-1$ & 7 & 0 & NA & NA \\
\hline & Composite & $4-6$ & $17-20$ & 6 & 0 & 7 & $0-1$ & $9-11$ & $6-10$ \\
\hline & Cluster & 0 & $5-6$ & $5-6$ & $0-1$ & NA & NA & NA & NA \\
\hline \multirow[t]{3}{*}{ Likelihood Mk1 } & Discretized & 0 & 14 & 6 & 0 & 7 & 0 & NA & NA \\
\hline & Composite & 6 & 19 & 6 & 0 & 7 & 0 & 9 & 9 \\
\hline & Cluster & 0 & 6 & 6 & 0 & NA & NA & NA & NA \\
\hline Likelihood asymmetrical & Cluster & 0 & 6 & 6 & 0 & NA & NA & NA & NA \\
\hline
\end{tabular}




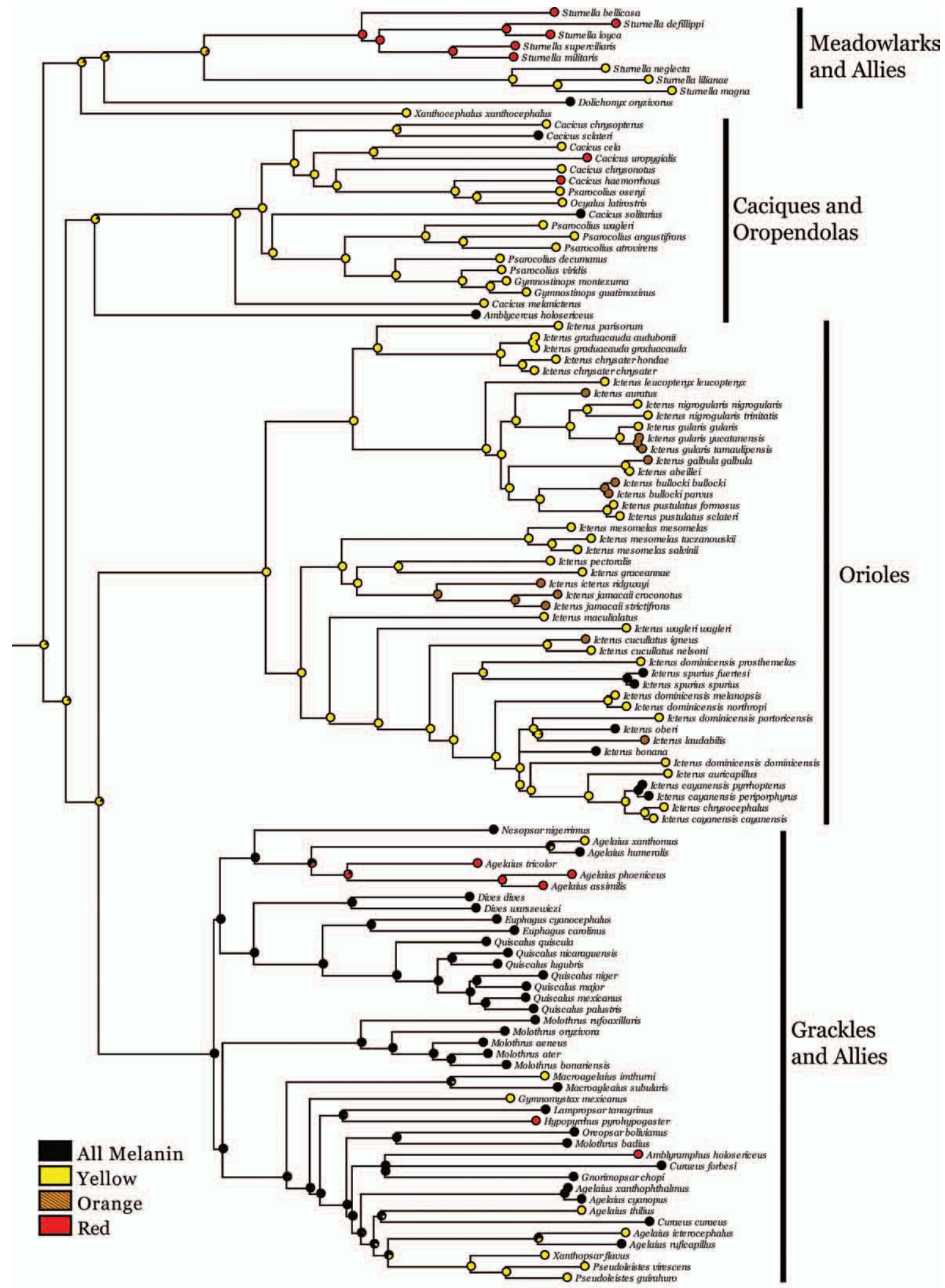

FIG. 4. Ancestral state reconstruction of our composite scoring of carotenoid coloration across Icteridae. This was calculated in MESQUITE (Maddison and Maddison 2010) using the likelihood method under a one-parameter rate model. Pie diagrams at each node indicate proportional likelihood scores, which describe degrees of support for each character state. 
Rather, the best-fitting two-parameter rate model (losses only slightly more likely than gains; $\mathrm{q} 12=3.90, \mathrm{q} 21=4.61$ ) also showed strong support for a scenario involving six gains of red coloration and also supported a yellow common ancestor (Table 2 and Fig. S4).

\section{Discussion}

Repeated gains of red coloration.-Our ancestral state reconstructions consistently indicated that there have been five or six independent gains of red carotenoid-based coloration in the New World blackbirds. The reconstructions showed that these gains occurred in the ancestor of the South American meadowlarks (genus Sturnella; five species), in the ancestor of the Red-winged Blackbirds (genus Agelaius; three species), and in four singlespecies lineages (Hypopyrrhus pyrohypogaster, Amblyramphus holosericeus, Cacicus haemorrhous, and C. uropygialis). Convergent gains of red coloration from a yellow ancestor were reported earlier in the caciques by Kiere et al. (2009). We found a similar pattern in two other blackbird clades: in the meadowlarks and allies, and in the grackles and allies. Our results strongly indicate that red carotenoid-based coloration evolved in Icteridae by repeated gains of red coloration from a yellow common ancestor. Although we were able to skew the likelihood rate model to force a result of repeated losses of red, this skewed model was a significantly worse fit to the data when compared to the best-fitting model. Thus, we have rejected a model of repeated losses of red as a plausible explanation for distribution of carotenoid coloration across the New World blackbirds.

The history of carotenoid-based coloration that we have inferred suggests the presence of a directional trend toward the repeated evolution of red plumage in this clade. We observed six changes in the direction of yellow to red and none in the reverse direction (Table 2; but see Figs. S1 and S2). Evolutionary history is replete with putatively directional trends, which may be indicative of active or passive processes driving the repeated evolution of characters (Carroll 2001). Hill has argued that such a pattern should arise from an active process, particularly the selection across lineages for female preference for redder males (Hill 1996, Hill and McGraw 2004). This argument is based on two sometimes controversial assertions that (1) selection should favor females that respond to more honest sexual signals (Krebs and Dawkins 1984) and (2) red carotenoid-based coloration is more costly and therefore a more honest signal of male condition (Hill 1996).

However, it is also important to consider the role of passive processes in producing apparent directional trends. Stochastic processes that follow bounded models of Brownian motion (Raup and Gould 1974, Gould 1988) also explain the repeated appearance of similar traits as lineages diversify, such as the trend toward larger body size in mammals (e.g., Cope's rule; Stanley 1973). Carotenoid color space may be similarly bounded: birds have never evolved carotenoid coloration that produces green or blue coloration, presumably because of biochemical constraints (McGraw 2006a). Assuming an ancestral state of yellow (which is the apparent lower bound), any drift would result in a directional trend. Simulations and broader comparative studies are needed that examine the trend that we have observed in blackbirds to explore whether it may be driven by active or passive processes and to determine whether similar trends are widespread across the passerine birds.
Ancestral yellow coloration.-Our results suggest that the common ancestor of the New World blackbirds most likely exhibited yellow plumage. However, it is worth mentioning that this conclusion depends on our assumption that the yellow plumage displayed on feather patches on different regions of the body was homologous. If this assumption is incorrect, our scoring of carotenoid coloration may have created a composite character made up of several independently evolved characters (McLennan and Brooks 1993). Scoring carotenoid coloration for each of these body regions independently leads to a reconstruction that they are each absent in the common ancestor. However, there are at present no data to support the assumption that carotenoid color patches on different body regions evolve independently. By contrast, recent studies in widowbirds and bishops that included chemical analysis of pigments have shown yellow coloration to be homologous in all their taxa that express it (Andersson et al. 2007, Prager et al. 2009). Here, we have assumed that yellow coloration is homologous across feather patches. To assess whether this assumption is valid our future studies of carotenoid coloration in the Icteridae will focus on the identity of the carotenoid pigments responsible for blackbird color variation.

We also observed seven repeated gains of orange coloration in the New World orioles from a yellow common ancestor. Hofmann et al. (2006) addressed the evolution of orange coloration extensively in their study of the oriole clade but inferred a different history for carotenoid-based coloration. Using continuous ancestral state reconstruction methods, they inferred an ancestral oriole with intermediate yellow-orange coloration and subsequent changes toward both yellow and orange coloration. Our inference of a yellow common ancestor is influenced greatly by the predominance of yellow coloration among the other icterids. Furthermore, we noted a conspicuous lack of orange feather coloration in our extensive sampling of blackbirds outside Icterus (Fig. 2A). Thus, we conclude that orange feather coloration in Icteridae is a novelty that was likely gained repeatedly within the oriole clade.

In conclusion, our results suggest that red coloration has been gained repeatedly in the New World Blackbirds from a common ancestor that exhibited yellow ornamentation. Thus, the elaborate red ornaments displayed by many blackbirds are likely convergent in origin. Furthermore, we have described an apparent directional trend toward red coloration in this clade that is similar to those described in previous studies of red and yellow coloration (Hill and McGraw 2004, Prager and Andersson 2010). These repeated inferences of directional trends toward red coloration suggest that this pattern could be common among passerine birds and may reflect either a general selection pressure or a stochastic directional process (Stanley 1973, Hill 1996). We will be directly exploring the ultimate causes of repeated gains of red coloration in blackbirds and we encourage other studies that investigate these questions using behavioral (e.g., Hansen and Rohwer 1986), phylogenetic (e.g., Hofmann et al. 2006), and mechanistic approaches (e.g., Andersson et al. 2007). Our next step will be to reconstruct the evolution of the carotenoid pigmentation underlying coloration in the New World blackbirds.

\section{ACKNOWLEDGMENTS}

Table S1 and Figures S1-S4 are available at dx.doi.org/10.1525/ auk.2011.11117. J. J. Price, C. M. Hofmann, and F. Jacobsen, as 
well as several anonymous reviewers, provided helpful advice on the manuscript. We thank the National Museum of Natural History, the Academy of Natural Sciences in Philadelphia, the Delaware Museum of Natural History, and the Field Museum of Natural History for allowing the Omland lab to measure specimens in their collections. We thank S. Lanyon and K. Barker for allowing us the use of their phylogeny for the Icteridae. K.E.O. was supported by a National Science Foundation CAREER grant DEB-0347083. The Omland lab is a member of the Smithsonian Ornithology Group. N.R.F. would like to thank P. and S. Everdell for prompting his interests in biology and nature.

\section{Literature Cited}

Allen, E. S., AND K. E. Omland. 2003. Novel intron phylogeny supports plumage convergence in orioles (Icterus). Auk 120:961-969.

Andersson, S., And M. Prager. 2006. Quantifying colors. Pages 41-89 in Bird Coloration. I. Mechanisms and Measurements (G. E. Hill and K. J. McGraw, Eds.). Harvard University Press, Cambridge, Massachusetts.

Andersson, S., M. Prager, and E. I. A. Johansson. 2007. Carotenoid content and reflectance of yellow and red nuptial plumages in widowbirds (Euplectes spp.). Functional Ecology 21:272-281.

Brush, A. H. 1967. Pigmentation in the Scarlet Tanager, Piranga olivacea. Condor 69:549-559.

Brush, A. H. 1990. Metabolism of carotenoid pigments in birds. FASEB Journal 4:2969-2977.

Brush, A. H., ANd D. M. Power. 1976. House Finch pigmentation: Carotenoid metabolism and the effect of diet. Auk 93:725-739.

Carroll, S. B. 2001. Chance and necessity: The evolution of morphological complexity and diversity. Nature 409:1102-1109.

Clements, J. F. 2007. The Clements Checklist of Birds of the World, 6th ed. Cornell University Press, Ithaca, New York.

DALE, J. 2006. Intraspecific variation in coloration. Pages 36-86 in Bird Coloration. II. Function and Evolution (G. E. Hill and K. J. McGraw, Eds.). Harvard University Press, Cambridge, Massachusetts.

Fox, D. L. 1962. Metabolic fractionation, storage and display of carotenoid pigments by flamingoes. Comparative Biochemistry and Physiology 6:1-40.

Fox, D. L., A. A. Wolfson, And J. W. McBeth. 1969. Metabolism of $\beta$-carotene in the American Flamingo, Phoenicopterus ruber. Comparative Biochemistry and Physiology 29:1223-1229.

Friedman, N. R., C. M. Hofmann, B. Kondo, and K. E. Omland. 2009. Correlated evolution of migration and sexual dichromatism in the New World orioles (Icterus). Evolution 63:3269-3274.

Gould, S. J. 1988. Trends as changes in variance: A new slant on progress and directionality in evolution. Journal of Paleontology 62:319-329.

HANSEn, A. J., AND S. Rohwer. 1986. Coverable badges and resource defense in birds. Animal Behaviour 34:69-76.

Hill, G. E. 1990. Female House Finches prefer colourful males: Sexual selection for a condition-dependent trait. Animal Behaviour 40:563-572.

Hill, G. E. 1996. Redness as a measure of the production cost of ornamental coloration. Ethology, Ecology, and Evolution 8:157-175.
HiLl, G. E., AND K. J. McGraw. 2004. Correlated changes in male plumage coloration and female mate choice in cardueline finches. Animal Behaviour 67:27-35.

Hofmann, C. M., T. W. Cronin, and K. E. Omland. 2006. Using spectral data to reconstruct evolutionary changes in coloration: Carotenoid color evolution in New World orioles. Evolution 60:1680-1691.

Hofmann, C. M., T. W. Cronin, and K. E. Omland. 2007a. Melanin coloration in New World orioles II: Ancestral state reconstruction reveals lability in the use of carotenoid and phaeomelanins. Journal of Avian Biology 38:172-181.

Hofmann, C. M., K. J. McGraw, T. W. Cronin, and K. E. OMLAND. 2007b. Melanin coloration in New World orioles I: Carotenoid masking and pigment dichromatism in the Orchard Oriole complex. Journal of Avian Biology 38:163-171.

Hudon, J. 1991. Unusual carotenoid use by the Western Tanager (Piranga ludoviciana) and its evolutionary implications. Canadian Journal of Zoology 69:2311-2320.

Inouye, C. Y., G. E. Hill, R. D. Stradi, and R. MontgomERIE. 2001. Carotenoid pigments in male House Finch plumage in relation to age, subspecies, and ornamental coloration. Auk 118:900-915.

Jacobsen, F., N. R. Friedman, and K. E. Omland. 2010. Congruence between nuclear and mitochondrial DNA: Combination of multiple nuclear introns resolves a well-supported phylogeny of New World orioles (Icterus). Molecular Phylogenetics and Evolution 56:419-427.

Jaramillo, A., And P. Burke. 1999. New World Blackbirds: The Icterids. Princeton University Press, Princeton, New Jersey.

Kiere, L. M., C. M. Hofmann, J. J. Price, T. W. Cronin, and K. E. Omland. 2009. Discrete evolutionary color changes in caciques suggest different modes of carotenoid evolution between closely related taxa. Journal of Avian Biology 40:605-613.

Kondo, B., And K. E. Omland. 2007. Ancestral state reconstruction of migration: Multistate analysis reveals rapid changes in New World orioles (Icterus spp.). Auk 124:410-419.

Krebs, J. R., and R. Daw Kins. 1984. Animal signals: Mindreading and manipulation. Pages 380-402 in Behavioral Ecology: An Evolutionary Approach, 2nd ed. (J. R. Krebs and N. B. Davies, Eds.). Sinauer Associates, Sunderland, Massachusetts.

LANYON, S. M., AND K. E. OMLAND. 1999. A molecular phylogeny of the blackbirds (Icteridae): Five lineages revealed by cytochrome- $b$ sequence data. Auk 116:629-639.

Maddison, W. P., And D. R. MAdDison. 2010. MESQUITE: A modular system for evolutionary analysis. [Online.] Available at mesquiteproject.org.

MAechler, M. 2005. CLUSTER: Cluster analysis basics and extensions: CLUSTER R package version 1.12.1. [Online.] Available at cran.r-project.org/.

McGraw, K. J. 2006a. Mechanics of carotenoid-based coloration. Pages 177-242 in Bird Coloration. I. Mechanisms and Measurements (G. E. Hill and K. J. McGraw, Eds.). Harvard University Press, Cambridge, Massachusetts.

McGraw, K. J. 2006b. Mechanics of melanin-based coloration. Pages 243-294 in Bird Coloration. I. Mechanisms and Measurements (G. E. Hill and K. J. McGraw, Eds.). Harvard University Press, Cambridge, Massachusetts. 
McGraw, K. J., K. Wakamatsu, A. B. Clark, and K. YasUKAWA. 2004. Red-winged Blackbirds Agelaius phoeniceus use carotenoid and melanin pigments to color their epaulets. Journal of Avian Biology 35:543-550.

MCLennan, D. A., AND D. R. Brooks. 1993. The phylogenetic component of cooperative breeding in perching birds: A commentary. American Naturalist 141:790-795.

Montgomerie, R. 2006. Analyzing Colors. Pages 91-147 in Bird Coloration. I. Mechanisms and Measurements (G. E. Hill and K. J. McGraw, Eds.). Harvard University Press, Cambridge, Massachusetts.

Murphy, T. G., D. HernándeZ-Muciño, M. Osorio-Beristain, R. Montgomerie, and K. E. Omland. 2009. Carotenoid-based signaling by females in the tropical Streak-backed Oriole. Behavioral Ecology 20:1000-1006.

Norris, D. R., P. P. Marra, R. Montgomerie, T. K. Kyser, And L. M. RATCLIFFE. 2004. Reproductive effort, molting latitude, and feather color in a migratory songbird. Science 306:2249-2250.

OmLAnd, K. E., And S. M. LANyon. 2000. Recontructing plumage evolution in orioles (Icterus): Repeated convergence and reversal in patterns. Evolution 54:2119-2133.

Prager, M., AND S. Andersson. 2010. Convergent evolution of red carotenoid coloration in widowbirds and bishops (Euplectes spp.). Evolution 64:3609-3619.

Prager, M., E. I. A. Johansson, and S. Andersson. 2009. Differential ability of carotenoid C4-oxygenation in yellow and red bishop species (Euplectes spp.). Comparative Biochemistry and Physiology B 154:373-380.

Price, J. J., N. R. Friedman, and K. E. Omland. 2007. Song and plumage evolution in the New World orioles (Icterus) show similar lability and convergence in patterns. Evolution 61:850-863.

Price, J. J., AND S. M. LANYON. 2002. Reconstructing the evolution of complex bird song in the oropendolas. Evolution 56:1514-1529.
Price, J. J., S. M. Lanyon, and K. E. Omland. 2009. Losses of female song with changes from tropical to temperate breeding in the New World blackbirds. Proceedings of the Royal Society of London, Series B 276:1971-1980.

Price, J. J., AND L. M. Whalen. 2009. Plumage evolution in the oropendolas and caciques: Different divergence rates in polygynous and monogamous taxa. Evolution 63:2985-2998.

Pryke, S. R., M. J. Lawes, and S. Andersson. 2001. Agonistic carotenoid signalling in male Red-collared Widowbirds: Aggression related to the colour signal of both the territory owner and model intruder. Animal Behaviour 62:695-704.

Pyle, P. 1997. Identification Guide to North American Birds, Part 1: Columbidae to Ploceidae. Slate Creek Press, Bolinas, California.

RAup, D. M., AND S. J. Gould. 1974. Stochastic simulation and evolution of morphology-Towards a nomothetic paleontology. Systematic Zoology 23:305-322.

SearCy, W. A., K. YasuKawa, And S. M. Lanyon. 1999. Evolution of polygyny in the ancestors of Red-winged Blackbirds. Auk 116:5-19.

Shawkey, M. D., ANd G. E. Hill. 2005. Carotenoids need structural colours to shine. Biology Letters 1:121-124.

Stanley, S. M. 1973. An explanation for Cope's rule. Evolution 27:1-26.

Wiens, J. J., C. A. Kuczynski, W. E. Duellman, and T. W. REEDER. 2007. Loss and re-evolution of complex life cycles in marsupial frogs: Does ancestral trait reconstruction mislead? Evolution 61:1886-1899.

Yasukawa, K., L. K. Butler, and D. A. Enstrom. 2009. Intersexual and intrasexual consequences of epaulet colour in male Red-winged Blackbirds: An experimental approach. Animal Behaviour 77:531-540.

Associate Editor: J. Klicka 